\title{
Forgiveness as an Intervention among Caregivers of Dementia Patients: Case Report
}

\author{
Toumpalidou $\mathbf{M}^{1 *}$, Egkiazarova $\mathbf{M}^{1}$, Iordan $\mathbf{A R}^{1}$ \\ and Tsolaki $\mathrm{M}^{1,2}$ \\ ${ }^{1}$ Alzheimer Hellas, Thessaloniki, Greece \\ 23rd Department of Neurology, Faculty of Medicine, \\ Aristotle University of Thessaloniki, Greece \\ *Corresponding author: Toumpalidou M, Alzheimer \\ Hellas, 164 K. Karamanlistr., P.C. 54248, Thessaloniki, \\ Greece
}

Received: August 08, 2017; Accepted: September 01, 2017; Published: September 08, 2017

\section{Case Presentation}

Mrs. Helena aged 56 years old, came to the Day Care Center of Alzheimer Hellas to ask for help with the care of her mother who has been diagnosed with dementia. She has joined our support group designed for caregivers and during the sessions she became aware of the burden that was holding her back. For her case, the support group centralizes on forgiveness intervention. The stages of forgiveness therapy are: i) recognition ii) acceptance iii) emotional cleansing iv) reconstruction and v) ultimate forgiveness [1].

Mrs. Helena opened herself up to us and admitted her ambiguous feelings she was experiencing regarding her mother's care. Anger, sadness and guilt were only a few of the feelings she was experiencing but overall, a strong inner power that led her afterwards to stay by her mother's side. There were many relatives and friends that advised her to institutionalize her mother. Mrs. Helena, however, could not bear to take such decision. She was very upset because when she went to her mother's house, she accused her of stashing her clothes or the food she was preparing was not delicious. Her concerns were also pointing her siblings who choose not to commit in the process of taking care or their mother's hardship which gradually led her to heavy negative feelings like sadness and anger that all of a sudden, dominated her life (stage of recognition).

While taking part of our group sessions, her anger appeared to have started back in her early childhood experiences when the circumstances forced her to grow up with her grandmother in Greece, away from her parents and siblings, who were all in Germany (emotional cleansing). That has been the point when the emotion immersed into her and she confessed that she has never opened herself up before. For Helena this new feelings were completely new as she used to be known as a well-balanced person and the one who is always ready to provide the support for others. She married young and gave birth twice, having two daughters with whom she developed an excellent friendly-fraternal relationship.

The love her new family brought into her life during these years made her forget the negative childhood memories she gathered. Yet, when her mom has been diagnosed with dementia, everything came back to her. She was caring an overwhelming burden since those childhood memories and after she opened herself to us, she decided to announce her leaving through a phone call as she was too fearful to face the past again. After a few phone calls we convinced her to join the group for one more meeting as the session needed a closure. In spite of her fear we decided to continue with the new step of the exercise (stage of acceptance).

This was a role-playing game where the past was interpreted in present from two different perspectives: the perspective of little Helena and the perspective of her mother. We asked a member of the group for help and the person was assign to perform little Helena's emotions that were described in the previous meeting while Helena was performing her mother's role emotions and struggles. Mrs. Helena has quickly adapted to the role play exercise and she also eagerly participate in others exercises. During the role she took as her mother, we have been all surprised to hear how vigorously and casually she defended those years her mother spend in Germany. The mother's pelage surprised the grief of leaving her daughter behind and the struggle of sacrificing her for a better future. Challenges were being faced from all directions and the decision of leaving her behind was not easy at all. "Back there everybody wanted to do better, to earn a nice pension and to be able to afford some quality food on the table. My mother-in-law also turned her back on me while I was pregnant with Helena and my son was too young at that time. There was this enormous tension that eventually knocked my spirit down and I had to make a decision" (stage of reconstruction).

Reaching the end, this exercise, has been proved to be a powerful experience not only for her but also for the entire group. After the person who was playing little Helen's feelings finished describing all the negative feelings she had felt in the past, Mrs. Helena stood up and embraced her overwhelmed and visibly redeemed. All her burden has been lifted that moment and the past was no longer a fear of hers.

Many meetings followed up and she gradually worked on the deepest insecurities that were gathered from her past relationship with her mother. Nevertheless, with the help of a housewife she hired, was taking care of her mother in her house and she confessed she is not physically nor psychically tired yet.
J Fam Med - Volume 4 Issue 6 - 2017

ISSN : 2380-0658 | www.austinpublishing group.com

Toumpalidou et al. (C) All rights are reserved
Citation: Toumpalidou M, Egkiazarova M, Iordan AR and Tsolaki M. Forgiveness as an Intervention among Caregivers of Dementia Patients: Case Report. J Fam Med. 2017; 4(6): 1127. 
Mrs. Helena came back after a while and told us her caregiver role took an end. She shared with us the last weeks she had with her mother (stage of ultimate forgiveness).

Even if she was not feeling tired, one day she started to worry that she might be forced to institutionalize her mother after all as there was not enough space in the house. She was enjoying every moment and her mother seemed peaceful and was cooperating very well. When she and her husband started to seriously consider a rehabilitation center, her mother was closer to the final goodbye than never.

The very next morning, Helena was asked by her mother to bring her a glass of water. Even if a plastic bottle was right beside the bed, she insisted in having the glass. When she brought it, she carefully helped her to drink it. Her mother said "thank you" and she asked for a piece of bread. Immediately Helena returned to the room with the bred. Meanwhile, her mother passed away...

For her, this was a second chance to live her childhood all over again, away from all the toxic feelings she had. It has been an unconditional pure bounding between mother and daughter. The time they spend together, recovered for all the lonely youth years. In the end, she happily showed her gratitude to us for persuading her to continue the sessions and gradually get rid of her toxic feelings.

\section{Conclusions}

There is extensive research evidence supporting that it is very common for the caregivers to experience high levels of burden and psychological morbidity. Therefore, supportive interventions for caregivers have been developed in order to face their needs $[2,3]$. Common interventions provided for caregivers are: (a) psychoeducational group, (b) family support intervention, (c) psychological support group, (d) relaxation intervention, etc. [4]. However, it seems that despite of all the effort they put into these interventions, some caregivers still continue to hold on to burden. Prior research has shown forgiveness to be a crucial intervention process in helping people to heal anger over betrayals, relieve depression and anxiety and restore peace of mind [5]. As far as dementia caregivers, behavioral problems related with burden have been found to be mediated trough forgiveness [6].

Mrs. Helena could not deal with the feeling of anger, guilt and sadness until she experienced the healing effects of forgiveness intervention despite the previous intervention strategies. During the support group sessions Mrs. Helena passed through all the stages of forgiveness therapy (recognition-acceptance - emotional cleansing, reconstruction) and came finally to the ultimate forgiveness. She opened up and interpreted the past under a new mature perspective initiating the process of healing and finally achieving "catharsis".

\section{References}

1. Akhtar S, Barlow J. Forgiveness Therapy for the Promotion of Mental WellBeing: A Systematic Review and Meta-Analysis. Trauma Violence Abuse. 2016. pii: 1524838016637079

2. Connell CM, Janevic MR, Gallant MP. The costs of caring: impact of dementia on family caregivers. Journal of psychiatry and neurology. 2001; 14: 179-187.

3. Dementia: a public health priority. World Health Organization. 2012.

4. Karagiozi K, Papaliagkas V, Giaglis G, Papastavrou E, Pattakou V, Tsolaki M. Combined intervention for caregivers of patients with dementia: a randomized controlled trial. International Journal of Academic Research in Psychology. 2014; 1: 77-91.

5. Wright LM. Softening suffering through spiritual care practices: one possibility for healing families. J Fam Nurs. 2008; 14: 394-411.

6. Cheng ST, Ip IN, Kwok T. Caregiver forgiveness is associated with less burden and potentially harmful behaviors. Aging Ment Health. 2013; 17: 930934.
J Fam Med - Volume 4 Issue 6 - 2017 ISSN : 2380-0658 | www.austinpublishing group.com Toumpalidou et al. @ All rights are reserved
Citation: Toumpalidou M, Egkiazarova M, Iordan AR and Tsolaki M. Forgiveness as an Intervention among Caregivers of Dementia Patients: Case Report. J Fam Med. 2017; 4(6): 1127. 